\title{
TranspareSer: Autonomia e Exercício de Direitos de um Coletivo de Pessoas Transexuais
}

\author{
Maria Ignez Costa Moreira ${ }^{1}$ \\ Celso Fernandes Patelli ${ }^{2}$ \\ ${ }^{1}$ Pontifícia Universidade Católica de Minas Gerais, \\ ${ }^{2}$ Centro de Referência de Assistência Social, MG, Brasil. \\ MG, Brasil.
}

Resumo: Este artigo apresenta o relato da experiência realizada junto aos participantes do grupo TranspareSer, formado por pessoas transexuais de Poços de Caldas - MG, a partir dos atendimentos realizados no equipamento público do CRAS. O grupo TranspareSer teve como objetivo possibilitar a realização da demanda de seus integrantes da mudança do registro civil, de modo que pudessem alcançar a congruência entre a identidade de gênero e o nome registrado em seus documentos. A mudança do registro civil, compreendida como estratégia de inclusão social e de reconhecimento de direitos desta população. O grupo foi coordenado pelo psicólogo do CRAS e essa experiência profissional foi objeto de reflexão em sua formação pós-graduada no nível do mestrado. A análise dessa experiência buscou compreender os atravessamentos institucionais, tanto no nível singular, quanto grupal e a construção da autonomia de seus participantes, tendo em vista a apropriação do espaço grupal e a recusa de serem tratados como sujeitos de direitos tutelados. A autonomia do grupo pôde ser percebida por meio da criação de regras próprias, da reconfiguração do grupo a partir da entrada de novos membros e da mudança de posição do coordenador do grupo. O processo grupal avaliado de modo processual indica como resultados a mudança do registro civil já alcançada por alguns de seus membros com efeitos tanto singulares quanto grupal e a construção de novo projeto que visa a transformação do grupo em uma ONG com o objetivo de oferecer apoio psicossocial, jurídico e de assistência médica às pessoas transexuais.

Palavras-chave: Transexuais, Assistência Social, Políticas Públicas, Psicologia, Processo Grupal. 


\title{
TranspareSer: Autonomy and Exercise of Rights of a Collective of Transgender People
}

\begin{abstract}
This article presents the report of the experience performed with the participants of the TranspareSer group, formed by transgender people from Poços de Caldas, MG, from the services performed in the public equipment of CRAS. The TranspareSer group aimed to enable the realization of the demand of its members related to the change of civil registration, so that they could achieve congruence between the gender identity and the name recorded in their documents. The change of the civil registration is understood as a strategy of social inclusion and recognition of the rights of this population. The group was coordinated by the psychologist of CRAS and this professional experience was the object of reflection in his postgraduate training at the master's level. The analysis of this experience sought to understand the institutional crossings, both at the singular and group levels, and the construction of the autonomy of its participants, in view of the appropriation of the group space and the refusal to be treated as subjects of protected rights. The autonomy of the group could be perceived through the creation of its own rules, the reconfiguration of the group from the entry of new members and the change of position of the group coordinator. The group process evaluated in a procedural way indicates as results the change of the civil registration already achieved by some of its members with both singular and group effects and the construction of a new project aimed at transforming the group into an NGO with the objective of offering psychosocial, legal and medical assistance support to transgender people.
\end{abstract}

Keywords: Transsexuals, Social Assistance, Public Policies, Psychology, Group Process.

\section{TranspareSer: Autonomía y Ejercicio de Derechos de un Colectivo de Personas Transexuales}

Resumen: Este artículo presenta la experiencia de los participantes del grupo TranspareSer, formado por personas transgénero de Poços de Caldas, MG, de los servicios prestados en las instalaciones públicas de CRAS. El propósito del grupo TranspareSer era hacer posible que los miembros del registro civil cambiaran sus demandas para que pudieran lograr congruencia entre la identidad de género y el nombre registrado en sus documentos. El cambio del registro civil, entendido como una estrategia de inclusión social y reconocimiento de derechos de esta población. El grupo fue coordinado por el psicólogo del CRAS y esta experiencia profesional fue objeto de reflexión en su formación de posgrado a nivel de maestría. El análisis de esta experiencia buscó comprender los cruces institucionales, tanto a nivel singular como grupal, y la construcción de la autonomía de sus participantes, en vista de la apropiación del espacio grupal y la negativa a ser tratados como sujetos de derechos protegidos. La autonomía del grupo podría realizarse creando sus propias reglas, reconfigurando el grupo a partir de la entrada de nuevos miembros y cambiando la posición del coordinador del grupo. El proceso grupal evaluado por el proceso indica como resultado el cambio en el registro civil ya logrado por algunos de sus miembros con efectos tanto singulares como grupales y la construcción de un nuevo proyecto destinado a transformar al grupo en una ONG con el objetivo de ofrecer apoyo psicosocial, legal y de asistencia médica para personas transexuales.

Palabras clave: Transexuales, Asistencia Social, Políticas Públicas, Psicología, Proceso Grupal. 


\section{Introdução}

Esse artigo narra a experiência de intervenção psicossocial com um grupo de pessoas transexuais. O grupo, nomeado como TranspareSer, teve origem em um equipamento público de assistência social, o Centro de Referência de Assistência Social (CRAS) da Zona Leste II, na cidade mineira de Poços de Caldas (MG), em 2017. Havia, entre as pessoas que integraram o grupo, a urgência da alteração dos nomes no registro civil e, por extensão em seus documentos, tais com RG/Carteira de Identidade, CPF, Título de Eleitor, entre outros. Essa demanda propiciou a agregação dessas pessoas.

Os participantes apontavam que a discordância entre o gênero, com o qual elas se identificavam e o nome grafado em seus documentos causava a elas constrangimentos e discriminações de diversas ordens. Narraram que muitas vezes a incongruência entre o nome declarado nos documentos e a apresentação corporal e estética delas dificultava ou mesmo impedia que tivessem acesso a direitos sociais, uma vez que gerava nos servidores ou agentes de serviços públicos suspeitas quanto à possível "falsidade ideológica".

Para a análise do processo do grupo TranspareSer foi considerada a perspectiva de Lane (1994) que destaca dois elementos:

1) O significado da existência e da ação grupal só pode ser encontrado dentro de uma perspectiva histórica que considere a sua inserção na sociedade; 2) o próprio grupo só poderá ser conhecido enquanto um processo histórico, e neste sentido talvez fosse mais correto falarmos em processo grupal, em vez de grupo (p. 81).

No processo do Grupo TranspareSer, as histórias singular, institucional e social se atravessam e se afetam mutuamente. Cada membro do grupo traz suas vivências de exclusão social, de sofrimento e de resistência. O CRAS, equipamento público de assistência social é surpreendido pelas demandas específicas trazidas pelas pessoas que vivem a condição de transexualidade e, percebe a necessidade de escutá-las, de aprender com elas e se colocar como mediador na construção da autonomia delas.

O momento em que as atividades do grupo se iniciam e se desenvolvem (2017-2018) é o mesmo no qual ocorrem muitas mudanças nos ordenamen- tos jurídicos brasileiros no que se refere à alteração do nome de pessoas transexuais. A mais significativa delas para o Grupo TranspareSer é a decisão de retirada da necessidade de abertura de um processo judicial, pois passa a ser possível a alteração do nome no registro civil pelo expediente administrativo realizado pelos cartórios de registro civil.

O grupo com característica de um grupo aberto, ou seja, que permite um fluxo contínuo de entrada/ saída ou de participação esporádica das pessoas contou com um número aproximado de doze participantes, com um núcleo que se manteve frequente a todas as reuniões. Os encontros incialmente foram planejados como quinzenais, no entanto também a periodicidade das reuniões sofreu alterações motivadas pelas necessidades providências de documentação e de apoio mútuo, em alguns momentos o grupo chegou a se reunir três vezes na semana. O projeto grupal foi elaborado em torno da pauta principal: a alteração do nome das pessoas transexuais no registro civil, e sua trajetória no TranspareSer foi marcada por tensões e negociações internas e também com os equipamentos públicos, revelando a resistência singular e grupal e a busca de autonomia retirando o grupo da posição de assujeitado e afirmando a posição de grupo sujeito, bem como os seus componentes a sair da posição de sujeitos de direitos tutelados para a condição de sujeitos autônomos.

Esta experiência de intervenção grupal possibilitou a articulação entre o exercício profissional da Psicologia na política pública de assistência social e a realização da pesquisa que visa contribuir para a elaboração crítica da prática e para a construção de novas possibilidades teórico-metodológicas, por meio da necessária articulação entre teoria e prática que permite a práxis. As reflexões foram guiadas pelos aportes teórico-metodológicos produzidos pela Psicologia social, que tratam da temática dos grupos, e pela categoria interdisciplinar de gênero.

\section{A trajetória do Grupo TranspareSer}

Inicialmente, o grupo foi formado com as diretrizes conhecidas pela equipe do CRAS, pois a metodologia dos grupos é prevista nos manuais das políticas públicas de assistência social, e consiste na promoção de encontros de famílias ou indivíduos com questões comuns, conduzidos por técnicos de nível superior do CRAS com o objetivo de suscitar reflexão sobre um tema de interesse das famílias, sobre as vulnerabili- 
dades, riscos e potencialidades, identificados no território, contribuindo para o fortalecimento dos laços comunitários, o acesso a direitos, o protagonismo, a participação social e a prevenção a riscos (Brasil, 2012).

Essas diretrizes da política pública de assistência foram tomadas e a equipe considerando as demandas comuns relatadas por essas pessoas "trans" já atendidas, propôs a formação de um grupo, a ser coordenado pelo profissional de Psicologia, como uma estratégia de intervenção coletiva que pudesse promover a troca de informações, minimizar danos, potencializar habilidades e garantir um lugar de pertencimento às pessoas transexuais e travestis, por meio das ações da política pública de assistência social.

O TranspareSer é a primeira experiência do município de Poços de Caldas e o seu caráter inovador não se restringe apenas ao contexto da cidade do interior de Minas, mas também ao fato de a realização de grupos com pessoas trans não serem comuns em equipamentos da política de assistência social, como foi possível compreender a partir de uma pesquisa na base do Scientific Electronic Library Online (SciELO), por artigos publicados no período compreendido entre 2009-2018.

Para a busca dos artigos foram utilizados os seguintes termos: "transexualidade" e "saúde" e encontrados 31 artigos; "trans" e "saúde" trouxe 96 artigos. A pesquisa realizada a partir dos termos "transexualidade" e "assistência social" encontrou dois resultados, e quando se utilizou os termos "trans" e "assistência social" foram encontrados outros dois títulos. No total no campo da saúde foram encontrados 127 artigos, enquanto, no campo da assistência social, quatro artigos. A discrepância entre o total de artigos publicados pelas duas áreas sugere que os equipamentos de políticas públicas de assistência social ainda sejam pouco demandados pelo público de pessoas "trans", bem como, ainda tenham poucas ofertas que possam atender às especifidades desse público.

A postura diretiva do coordenador do grupo revelou-se como um primeiro descompasso entre as diretrizes do equipamento público e as particularidades do universo das pessoas transexuais. Uma prática comum na atuação do CRAS é a busca ativa por indivíduos e famílias em situação de vulnerabilidade, e no período de formação do grupo o Coordenador iniciou uma busca ativa pelas travestis, a maioria delas profissionais do sexo que atuavam na cidade. O psicólogo coordenador foi até os pontos de trabalho delas para propor a participação no grupo. Foi percebido que a presença dele causou incomodo nas travestis e, nenhuma delas compareceu à reunião para a qual haviam sido convidadas.

No contato seguinte com as transexuais que aderiram ao projeto do grupo o psicólogo foi esclarecido que elas não aceitavam a inclusão das travestis no grupo. Elas vão delineando o espaço grupal com as suas especificidades: travesti e transexual não se equivalem, as travestis são vistas como profissionais do sexo ao passo que as transexuais, não necessariamente. As transexuais temiam que ao serem confundidas com as travestis tivessem ainda mais dificuldades de encontrarem um trabalho formal e de serem respeitadas em seus direitos.

Esse episódio revelou que as pessoas transexuais e travestis não figuram entre o público prioritário da política pública de assistência social. Há poucos documentos de orientação para os profissionais da política pública de assistência social, por exemplo documento intitulado "SUAS sem transfobia" (s.d) disponibilizado pelos Ministérios de Direitos Humanos e Desenvolvimento Social (extintos em 2016 e substituídos pelo Ministério da Mulher, da Família e dos Direitos Humanos). Neste texto é retomada a orientação para a operacionalização do nome social a partir Decreto $n^{\circ} 8.727 / 2016$; tratada a definição do dia 29 de janeiro como Dia Nacional da Visibilidade Trans e apresentado um pequeno glossário dos termos transfobia, transexuais, identidade de gênero e orientação sexual.

Esse episódio também propiciou mudanças nas relações entre os participantes do grupo e o psicólogo do CRAS, que deixou a posição de um condutor diretivo do grupo, e que passou a atuar como mediador das demandas do grupo que eram dirigidas a outros equipamentos tais como o sistema judiciário e os de saúde.

A elaboração e escolha do nome grupo é outro momento marcante no processo de construção da autonomia do grupo. O nome TranspareSer é uma expressão com muitos sentidos. Na palavra composta encontramos o termo "trans" como uma marca identitária afirmativa, e que remete ao "transparecer", em um jogo de sentidos com a visibilidade das pessoas trans entre o aparecer e o ser transparente, entre ser visível e invisível.

A palavra TranspareSer grafada com S e não $C$, denúncia um erro aparente, pois o significante "Ser", afirma a ontologia trans que reclama reconhecimento 
de uma vida que merece, que deve e carece de ser vivida. Ainda sobre essa condição do ser e do nome, destaco uma situação bem ilustrativa onde um dos participantes faz uma piada sobre a grafia do nome e o "S" em maiúsculo: "parece errado, mas foi de propósito e está certo mesmo”. Nesse sentido, a grafia de TranspareSer denuncia as normas da gramática sexual que só reconhece a identidade trans como erro, desvio ou patologia (Butler, 2018; Preciado, 2014).

$\mathrm{O}$ ato de nomear-se coloca em evidência a forma de existência desejada. Os participantes, que vinham trabalhando na tentativa de terem os nomes que escolheram para serem reconhecidos, ao definirem um nome para o grupo, afirmam o que ele é: um grupo de gestão autônoma que não tem sua existência dependente de um equipamento público. "As oficinas realizadas pelo CRAS não tinham nome, o TranspareSer tem". A nomeação marca o momento em que os participantes assumem a condução do grupo.

O acompanhamento da trajetória do TranspareSer, os conflitos e as mudanças registrados no percurso demonstram a necessidade de melhor preparo da política de assistência social e seus equipamentos frente à a demanda da população transexual. Além disso, essa experiência mostra a formação permanente do psicólogo que é afetado em sua prática e transforma-se.

\section{A oficina: método de trabalho no TranspareSer}

Segundo Afonso (2006) a metodologia das "oficinas" pode ser compreendida como um trabalho realizado com grupos, sem um número predeterminado de encontros ou de participantes, essa flexibilidade se constituiu com uma marca do grupo TranspareSer.

Como já sinalizado o objetivo comum entre os participantes do grupo TranspareSer era a mudança do registro civil, que demandava de todos uma série de providências. Para que estas pudessem ser tomadas era necessário o acesso às informações e à compreensão das dificuldades subjetivas de enfrentamento desse processo.

A proposta metodológica da oficina foi adequada a esse objetivo, pois possibilita a elaboração de uma temática significativa no contexto pessoal e coletivo dos membros do grupo. A elaboração envolve a circulação de informações e conhecimentos já formalizados e transmitidos pelo psicólogo coordenador do grupo e pelos agentes implicados nos equipamentos responsáveis pela operacionalização para a mudança do registro civil, bem das experiências e saberes não formalizados pelos próprios participantes do grupo.

A oficina é uma metodologia de trabalho grupal que envolve a todos os membros do grupo de maneira integral, valorizando e possibilitando a expressão das diversas formas de pensar. As manifestações emocionais e os conflitos também podem ser feitas livremente pelos participantes, e estas manifestações serão objeto de reflexão. A metodologia das oficinas valoriza os diferentes saberes de seus membros, de forma que todos ensinam a todos, e todos aprendem com todos. Neste sentido, vale ressaltar a riqueza de aprendizagem produzida pelo Grupo TranspareSer pelos seus membros e profissionais envolvidos.

\section{Apresentação e discussão dos resultados (parciais) da trajetória do TranspareSer}

A criação do Grupo TranspareSer produziu efeitos na própria organização dos serviços prestados pelo CRAS em Poços de Caldas, pois foi a partir do contato com as pessoas trans, que a equipe de atendimento nomeada como "Núcleo da Mulher" decidiu alterar o seu nome para "Núcleo de violências de gênero" com o objetivo reconhecer não apenas as violências sofridas pelas pessoas cis como seu público-alvo, mas buscando incluir tanto as mulheres e homens homossexuais, quanto a população trans que sofrem violências e violações de seus direitos como público prioritário da política de assistência social.

Embora a ampliação dos objetivos de atendimento traçados pelo "Núcleo de violências de gênero" dos objetivos seja positiva, as demandas de homossexuais, transexuais e travestis dirigidas ao CRAS ainda é considerada pequena, tanto pelo reconhecimento do Núcleo da Mulher pela população, quanto pela associação do termo gênero às mulheres cis ou mesmo pelo desconhecimento do termo gênero.

Além das questões da organização da política pública de assistência social que não oferecia um espaço instituído para as demandas específicas de homossexuais e transexuais, a escassez de demandas desse público para o CRAS, pode também ser compreendida como uma atitude dessa população em se manter em certa invisibilidade como uma estratégia de autoproteção e evitação de violência, discriminação e preconceitos a ela dirigidas.

O grupo enfrentou na fase de sua implantação alguns obstáculos, pois como se tratava de um grupo atípico, do ponto de vista da organização CRAS, pois 
não havia uma normativa técnica para essa atividade, e não havia nenhum precedente no município de um grupo semelhante, algumas dificuldades de ordem burocrática surgiram. Um CRAS atuaria sobre diferentes territórios? Quais seriam os atores? Como registrar as atividades do grupo nos diferentes sistemas que geram os relatórios do número de atendimentos realizados em cada um dos CRAS do município? A demanda institucional, de produção de relatórios, indicadores e metas por vezes constitui uma dificuldade na execução de uma intervenção inovadora. Foi necessária a produção de arranjos para o grupo finalmente pudesse iniciar as suas atividades e um espaço localizado no centro da cidade, considerando a maior facilidade de acesso dos participantes.

Depois de superados todos os entraves institucionais foi agendada a primeira reunião do grupo, em um Centro Cultural. A divulgação foi feita por meio dos jornais, programas de rádios e TVs locais. Na data marcada para o primeiro encontro compareceram apenas três pessoas, no entanto a troca de informações a respeito dos direitos sociais e de saúde foram proveitosas. Houve consenso de que a questão mais importante para pessoas trans era a alteração do nome nos registros civis. As três participantes decidiram criar um grupo no aplicativo WhatsApp para promover a inclusão de outras pessoas trans conhecidas e combinar novos encontros.

Sob a pauta da alteração do nome nos registros civis mais pessoas passaram a frequentar o grupo e colaborar com suas atividades. Os participantes traziam histórias dos processos vividos por pessoas conhecidas que alteraram seus nomes. Um relato recorrente foi o de que a criação de mutirões pelos órgãos dos judiciários era uma estratégia facilitadora do processo. Para compreender melhor essa estratégia os participantes decidiram convidar um representante da defensoria pública para esclarecer sobre a viabilidade de criação de um mutirão na cidade. $O$ psicólogo coordenador do grupo fez a mediação para o convite. O grupo se apresentava como ativo e envolvido para a realização do seu objetivo.

O coordenador da Defensoria compareceu à reunião e explicou que o mutirão era possível somente em cidades maiores, nas quais havia um juiz responsável apenas pelos registros civis, e esta não era a condição de Poços de Caldas. Ele sugeriu que os participantes entrassem individualmente com processo judicial normal solicitando a alteração somente do nome, considerando que esta demanda teria maior possiblidade de sucesso em um prazo menor. Em um segundo momento, também individualmente cada um poderia abrir um novo processo judicial reivindicado a alteração da indicação do sexo, independentemente da pessoa ter se submetido à cirurgia de transgenitalização, no entanto também esclareceu que alguns juízes entendiam que o sexo poderia ser alterado no registro civil e demais documentos, apenas após a realização da cirurgia de transgenitalização.

As/os participantes do grupo concordaram prontamente com a proposta do representante da Defensoria Pública e relataram que o nome incongruente com o gênero era o que lhes gerava maior constrangimento. Entendiam que a marcação do sexo nos documentos, que revela o reconhecimento do sexo com o qual a pessoa se identifica, além de ter efeitos práticos, tais como para o cálculo da aposentadoria ou para a dispensa do alistamento militar causava menores problemas, pois não é uma informação com menor publicidade.

O nome próprio expõe as pessoas na cena pública, ser chamado pelo nome social feminino e apresentar um documento de identidade com um nome masculino ou ser chamada por um nome social masculino e apresentar um documento de identidade com um nome feminino acarretava não raras vezes questionamentos em equipamentos públicos de saúde, nas escolas, em eventos culturais, por exemplo. E a estranheza causada nas pessoas presentes nestas cenas públicas frente a diferença entre o nome e apresentação de gênero é um elemento causador de sofrimento psicossocial, essas declarações compartilhadas no grupo confirmam confirma a relevância do nome como legitimador da identidade de gênero (Alves, 2018; Preciado, 2014).

Passados uns meses do início do grupo, em novembro de 2017, uma juíza do município entrou em contato com a Defensoria Pública e com o grupo TranspareSer trouxe uma nova a possibilidade de fazer as alterações de nome e sexo pelo Centro Judiciário de Solução de Conflitos e Cidadania (CEJUSC), que dispensaria o processo judicial e a solução da questão seria alcançada em menor tempo. Para a realização desse procedimento o/a interessado/a deveria apresentar os seguintes documentos: RG, CPF e título de eleitor; certidões negativas, civis e criminais; e laudos, médicos e psicológicos que "atestassem" a transexualidade. Após a verificação dos documentos o CEJUSC 
geraria um mandato para o Cartório de Registro Civil expedir as novas certidões.

Os(as) participantes de posse dessas informações se dispuseram a conseguir os documentos requeridos, aqueles que tinham maior facilidade com o trato com a burocracia ajudavam os demais. Essa atitude revelou que os membros do grupo construíram vínculos e reconheciam-se como parte de um grupo com um objetivo comum. A conquista dos novos documentos por cada um dos membros passou a significar uma conquista de todos.

O levantamento dos documentos e apresentação dos mesmos ao CEJUSC foi se revelando como uma rota crítica, no sentido de que ela foi marcada por situações de constrangimento e sofrimento psicossocial. Embora, informadas/os de seus direitos e seguindo as orientações dadas os/as participantes do CEJUSC viram-se submetidas às interpretações e valores pessoais dos servidores públicos. São muitos os exemplos, a cada entrega de um conjunto de documentos um novo pedido era agregado, como o do certificado de reservista do exército feito às participantes mulheres trans. Essas situações constrangedoras eram relatadas e elaboradas no grupo, o que foi fundamental para que elas/eles prosseguissem.

A solicitação arbitrária de alguns documentos relevava o preconceito, a discriminação, a intolerância com as pessoas que rompem com a lógica heteronormativa. Cada novo documento exigido e não apresentado retardava o fluxo do processo. Embora não existissem pais ou mães no grupo foram exigidas as certidões de nascimento dos filhos, o que exigia uma ida ao equipamento para explicar que não havia os filhos. Após a apresentação de uma cópia do imposto de renda, outra mais atualizada era exigida, depois documentos de bens como casa ou carro, mesmo quando as pessoas não eram proprietárias de nenhum bem. A apresentação de um passaporte vencido, a comprovação de quitação de tributos e impostos.

Quando uma das participantes se queixou das sucessivas solicitações de documentos e dos adiamentos da liberação do mandato para o Cartório de Registro Civil expedir o novo registro civil, teve como resposta da atendente "que esse tipo de processo é uma excepcionalidade não prevista no Direito e que então deveria ser assim mesmo, complicado". O subtexto nos permite ler que o processo é tomado à moda de um ritual iniciático que causa sofrimento e testa a resistência emocional dos sujeitos.
A fala desta atendente ilustra o pensamento de Bento (2014) sobre os direitos de minorias sexuais ao longo do país:

a conquista de direitos que deveriam ser plenos desde o primeiro momento foi sendo legislada pouco a pouco. É como se houvesse um subtexto direcionado aos excluídos: calma, vamos ver o quanto você resiste e se você acredita mesmo que "merece" adentrar no reino da cidadania (p. 172).

Em março de 2018, o Supremo Tribunal Federal (STF) declarou a possibilidade de alteração de nome e gênero no registro civil de pessoas trans, dispensados o laudo médico e a cirurgia de redesignação de transgenitalização. Alguns participantes entraram em contato com o CEJUSC buscando esclarecimentos sobre a repercussão dessa decisão do STF em seus processos. Foram informados/as não haveria alterações imediatas pois, ainda faltava um provimento que regularia a decisão do STF, o que provavelmente demoraria alguns meses. Sobre a exigência do laudo médico, dispensado pelo STF, o posicionamento do CEJUSC é de que seria mantido, pois constituía uma garantia de que a pessoa que pretendia a mudança é estável do ponto de vista psíquico.

O processo para a alteração do nome no registro civil vivenciado pelos membros do grupo TranspareSer reafirma a consideração de (Souza, 2016) de que o direito ao nome congruente com a identidade de gênero das pessoas trans está submetido às flutuações das opiniões individuais dos agentes públicos, e que tais flutuações e o hiato entre a prescrição legal e a prática cotidiana são geradoras de sofrimento psicossocial. Neste sentido, o espaço do grupo TranspareSer foi de grande importância para sustentação emocional das pessoas que viveram o processo de alteração do registro civil. Essa experiência reforça que a busca pelos direitos e o exercício pleno da cidadania não está dissociada das vivências afetivas, da afirmação da identidade e do reconhecimento das pessoas trans. Além de acolher as pessoas em momento de sofrimento, o grupo TranspareSer é uma experiência que potencializa os recursos simbólicos e emocionais de seus membros.

As políticas públicas de assistência social são muito importantes na superação da condição de precariedade da vida de alguns grupos populacionais. Butler (2018) traça uma distinção entre a vul- 
nerabilidade humana e a precariedade. Podemos compreender que a vulnerabilidade humana tem um traço ontológico, os seres humanos nascem em condição de vulnerabilidade dependem do cuidado para que sobrevivam, seres humanos são vulneráveis, são finitos.

No entanto, a precariedade da existência está associada ao modo como vida é organizada, como são distribuídos e acessíveis os bens materiais e simbólicos necessários à vida digna, à vida boa. A vida humana depende de cuidados para prosperar, essas condições são produzidas.

Butler (2018) segue considerando que precariedade humana é politicamente induzida, por ação ou omissão do Estado. Ação como no caso das guerras ou da violência policial, omissão, pela falta de intervenção sobre questões específicas, como a falta de políticas frente ao alto índice de assassinatos de pessoas trans. A exclusão de pessoas trans é produzida e denunciada, por exemplo, no impedimento do uso de banheiros em locais públicos, segundo a identidade de gênero e não ao sexo biológico.

Os participantes do TranspareSer narraram em diversos momentos a precariedade a que estavam expostos ao dividir suas histórias, suas experiências frente às entrevistas de emprego frustrantes, o atendimento constrangedor em instituições públicas ou as intervenções corporais feitas na clandestinidade na falta de acesso aos equipamentos públicos de saúde e de atendimentos de qualidade técnica e humana. Com o passar dos encontros, o compartilhamento das diversas experiências vai sendo feito de forma clara, mostrando o fortalecimento dos vínculos grupais, vai se instituindo uma solidariedade mútua. O processo grupal foi potencializado tanto as pessoas de dele participam, quanto a própria instância do grupo. Os/as participantes vão se configurando como grupo, criando novas possibilidades de enfrentamento de suas necessidades e demandas.

O grupo TranspareSer se estruturou a partir da demanda de mudança do registro civil e no momento atual está construindo um novo projeto comum que é a sua instituição como uma organização não governamental (ONG). Diferentes razões somaram-se para que os participantes decidissem que o TranspareSer se torne uma ONG. Uma delas é que, depois de algumas tensões vividas com diferentes instituições públicas o grupo passou a considerar que a sua institucionali- zação seria uma forma de proteção, conferindo peso às demandas individuais e coletivas, garantindo certa impessoalidade às reclamações e denúncias, de forma a evitar retaliações pessoais.

Além disso, a decisão pela formação da ONG também foi tomada na esperança de que a autonomia do grupo possa resultar em geração de renda, que possa amparar as necessidades de atendimento de saúde, dos processos judiciais e capacitação profissional, e enfim ações que visam a inclusão social dos seus membros.

A decisão do Grupo TranspareSer por sua transformação em ONG levou a uma autoavaliação, quanto à exclusão das travestis que havia sido feita no início da formação do grupo. As/os participantes decidiram ampliar o público-alvo do grupo, incluindo toda a população LGBT+, nas palavras de um dos participantes "todo mundo fora da caixinha", mesmo as travestis. Essa decisão pode ser atribuída ao processo grupal que possibilitou a reflexão e elaboração das experiências vividas coletivamente na interação com as diferentes instituições públicas e o reconhecimento das condições precárias vividas não só pelas/os transexuais, mas toda a população LGBT+. Neste sentido, o grupo superou a reprodução da exclusão vivida por eles/elas.

Esse tipo de associação de diferentes grupos, não se dá função de um núcleo identitário comum, mas da precariedade compartilhada à qual todos/todas estão expostos, na expressão de Butler (2018) a aliança dos corpos, visa dar visibilidade às condições precárias a que essas populações são submetidas pelo Estado e tem a potência de produzir resistências e novas formas de organização da vida.

\section{Considerações finais}

A experiência relatada nesse artigo mostra a intersecção entre a experiência profissional do psicólogo que atua em um equipamento público de assistência social - CRAS, e a formação acadêmica no âmbito de uma pesquisa de mestrado em Psicologia. A associação da prática com a reflexão teórica produz afetações na postura do psicólogo, gera aprendizagens e novos questionamentos.

A Psicologia acumulou em sua trajetória científica e profissional de conhecimentos sobre as práticas grupais, esse conhecimento é dinâmico e renovado com a emergência de novas demandas. A assistência social, alçada à condição de política 
pública desde a promulgação da Constituição de 1988, tem demandado a atuação do psicólogo junto aos grupos sociais, famílias e indivíduos excluídos e precarizados. Entre eles emerge uma população até então invisibilizada: homossexuais, transexuais, travestis.

A utilização da metodologia das oficinas de grupo proporcionou uma tomada de posição ativa por parte dos membros do grupo e questionamentos quanto à própria organização e condução de alguns serviços prestados pelos equipamentos públicos de assistência social.
A experiência com o grupo TranspareSer fornece evidências das possibilidades e dos desafios de trabalho do psicólogo na política pública de assistência social. A garantia dos direitos sociais, a inclusão social dos membros do TranspareSer revela a necessidade da consideração da dimensão psicossocial, da potencialidade dos grupos e dos sujeitos compõem. Essa experiência aqui narrada mostra que os sujeitos das políticas públicas de assistência social são ativos, não pode ser reduzido a sujeitos de direitos tutelados, o trabalho que se realiza nesse campo deve ser com os sujeitos e não para os sujeitos.

\section{Referências}

Afonso, M. L. (2006). Oficinas em dinâmica de grupo: Um método de intervenção psicossocial. São Paulo, SP: Casa do Psicólogo.

Bento, B. (2014). Nome social para pessoas trans: Cidadania precária e gambiarra legal. Contemporânea, $4(1), 165-182$

Alves, C. E. R. (2017) Nome sui generis: O nome (social) como dispositivo de identificação de gênero. Belo Horizonte, MG: PUC Minas.

Brasil. Ministério do Desenvolvimento Social e Combate a Fome. (2012). Orientações técnicas sobre o PAIF (Vol. 2). Brasília, DF: o autor.

Butler, J. (2018). Corpos em aliança e a política das ruas: Notas para uma teoria performativa de assembleia. Rio de Janeiro, RJ: Civilização Brasileira.

Lane, S. (1994) O processo grupal. In Silvia T. M. Lane, \&W. Codo (Orgs.), Psicologia social: O homem em movimento (pP.78-98). São Paulo, SP: Brasiliense.

Preciado, B. (2014) Manifesto contra-sexual. São Paulo: n-1 edições.

Provimento n. 73, de 28 de junho de 2018. Dispõe sobre a averbação da alteração do prenome e do gênero nos assentos de nascimento e casamento de pessoa transgênero no Registro Civil das Pessoas Naturais (RCPN). Diário de Justiça Eletrônico, 29 jun. 2018.

Souza, T. S. (2016). O nome que eu (não) sou. Rio de Janeiro, RJ: Lumen Juris.

\section{Maria Ignez Costa Moreira}

Docente da Faculdade de Psicologia do Programa de Pós-Graduação em Psicologia da Pontifícia Universidade Católica de Minas Gerais, Belo Horizonte - MG. Brasil.

E-mail: maigcomo@uol.com.br

(iD https:// orcid.org/0000-0003-3602-9609

\section{Celso Fernandes Patelli}

Psicólogo do Centro de Referência de Assistência Social (CRAS), Poços de Caldas - MG. Brasil.

E-mail: celsopatelli@gmail.com

(iD https:// orcid.org/0000-0001-9986-4180

Endereço para envio de correspondência:

Rua Úrsula Paulino, 409 apto. 402 - bloco 6 - Bairro Betânia. 30.570.000 - Belo Horizonte - MG 
Recebido 10/09/2019

Aceito 04/10/2019

Received 09/10/2019

Approved 10/04/2019

Recibido 10/09/2019

Aceptado 04/10/2019

Como citar: Moreira, M.I.C \& Patelli, C. P. (2019). TranspareSer: autonomia e exercício de direitos de um coletivo de pessoas transexuais. Psicologia:Ciência eProfissão, 39(n.spe3), 103-112.https://doi.org/10.1590/1982-3703003228497

How to cite: Moreira, M.I.C \& Patelli, C. P. (2019). TranspareSer: autonomy and exercise of rights of a collective of transgender people. Psicologia:Ciência e Profissão, 39(n.spe 3), 103-112.https://doi.org/10.1590/1982-3703003228497

Cómo citar: Moreira, M.I.C \& Patelli, C. P. (2019). TranspareSer: autonomía y ejercicio de derechos de un colectivo de personas transgênero. Psicologia: Ciência e Profissão, 39(n.spe 3), 103-112. https://doi.org/10.1590/1982-3703003228497 